\title{
Work Environment, Job Satisfaction, Top Employees Work Interests
}

\author{
A.S. Leaflet R 2166 \\ James Kliebenstein, Professor, Iowa State University, \\ Terrance Hurley, Associate Professor, University of \\ Minnesota, \\ Peter Orazem, Professor, Iowa State University, \\ Dale Miller, editor, National Hog Farmer, and \\ Steve May, publisher, National Hog Farmer
}

\section{Summary and Implications}

A survey of pig producers and employees was conducted to document rends in the industry. These surveys have been conducted four times: 1990, 1995, 2000, and 2005. Trends show that hours worked per week in 2005 declined from the 2000 levels. Employees indicated that they worked, on average, 45.3 hours per week in 2005 as compared to 48.7 hours in 2000, a decrease of 7 percent. The typical U.S. worker reported the average work week to be 33.8 hours, 25.4 percent less than the level reported by pig production employees.

Flexibility of work schedules appears to be increasing again. In 199526 percent of employees indicated that their weekend schedules were flexible or staggered by working part of Saturday or Sunday. In 2000 only 17.8 percent of employees reported this flexibility. This increased back to 20.6 percent of employers in 2005.

Dust masks or respirators were provided by most producers $(89.2 \%)$ and available to most employees $(92.2 \%)$. However, the use of dust masks and respirators is low. Only one in four employees used them and one-third of producers used them. Ear protection was worn by a larger share of employees $(64.5 \%)$.

The rapid increase in the size of hog production facilities and their increased reliance on hired labor requires producers to be able to manage personnel. Use of employer handbooks, written job descriptions, work plans, work reviews and evaluations can help with this task. Surveys indicate that the majority of producers do not take advantage of these methods. However, the use of methods such as employer handbooks, written job descriptions, work plans have increased from 1990 to 2000 . Interestingly, their use declined from 2000 to 2005 .

Employee satisfaction is high. In $200579.9 \%$ of employees indicated that they were either satisfied or very satisfied. Satisfied employees tend to work harder and are less likely to call in sick and are more productive.
Employee aspirations and attitudes toward the pork industry have changed over time. For example, fewer employees want to own their own operation some day. They are looking at the industry as where they will be employed. Also, a high percentage $(81.4 \%)$ felt their salary and benefits were competitive in their community. Women were less likely to feel this way.

\section{Introduction}

The pig production industry is experiencing changes in employment trends. As firms grow the need for employees grows as well. To document some of the changes a survey was conducted in late 2004 (2005 survey) of pig production employees and employers. This is the fourth survey in a 15 year span. The goal of the survey was to track changes in the employment market for pig production. Results of the 2005 survey are compared to the previous three surveys conducted in five year intervals $(2000,1995$, and 1990).

Competitive wages and fringe benefits are just the first step in making an operation more attractive to employees. Favorable working conditions are also high on employee's priority lists. Operations that consistently work their employees 60 hours, six to seven days/week may find it harder to retain those employees. Studies have shown that employees are also willing to accept lower wages in order to work in better environments. Employees also indicate that the mere availability of a dust mask or respirator is a positive benefit.

There are important tradeoffs for employers to consider. For example, the cost of hiring an additional employee may be well worth the investment if it reduces hours worked weekly or provides more weekend time off. Upgrading facilities to make them safer and more pleasant to work in is usually a good investment, too. These types of strategic expenditures will help attract topnotch employees and improve retention rates.

\section{Materials and Methods}

As indicated, there was the fourth survey in a 15 year span. A mail questionnaire was sent to pork producers and employees across the United States. Select questions in both surveys overlapped so that responses could be compared in key areas.

The National Hog Farmer qualified mailing list provided a select sample of producers/owners. A random sample of producers with an annual 
production of 3,000 head or more, or verified with 100 sows or more, were surveyed. All employees on the National Hog Farmer list were sent the survey.

Responses were tabulated to identify averages and differences. Not everyone answered every question, so the number of respondents may vary slightly with each question.

Iowa State University and University of Minnesota economists teamed with National Hog Farmer and Pfizer Animal Health to conduct the study.

\section{Results and Discussion \\ Typical Workweek}

Pork production employees endure a strenuous workweek compared to the average civilian employee. Generally, they work longer hours, work more days and get fewer weekends off.

Hours worked per week have declined from the 2000 levels (Table 1). Employees indicated they worked, on average, 45.3 hours per week, which is 3.4 hours $(7.0 \%)$ less than for $2000(48.7 \mathrm{hrs})$. This is a favorable trend as hours worked per week had increased from 1990 to the 1995-2000 time period. By comparison, the average work-week reported by the Bureau of Labor Statistics in 2005 was 33.8 hours. This is $25.4 \%$ less than the average reported by hog farm employees. Thus, while annual salaries in the pork industry are now closer to the U.S. average, pay/hour worked in substantially lower in the pork sector.

Some interesting discrepancies emerge when the hours producers expect employees to work are compared to the hours employees reported working. In 1990, producers expected employees to work 46.7 hour/week on average. This was 1.5 hours more than employees reported working. In 1995, producers expected employees to work 45.2 hours/week, and in 2000 that expectation rose to 46.5 hours/week. This was four hours less than employees reported in 1995 and two hours less than those reported in 2000. The two hour difference remained in 2005; producers reported 43.2 hours and employees 45.3 hours.

Much of the discrepancy is seen in the more than 50-hours/week tabulation. In 2005, workweeks of more than 40 hours were reported by $63 \%$ of producers and $72.6 \%$ of employees. However, $50.3 \%$ of producers expected their employees to put in a 4150 -hour workweek compared to $44.9 \%$ of the employees. The big difference was in the greater than 50 hour's category. Only $12.7 \%$ of the producers expect their employees are working more than 50 hours/week, while $27.7 \%$ of the employees report doing so. And, $15 \%$ of employees say they work more than 60 hours/week, but about $5 \%$ of the producers acknowledge their employees put in that many hours. The percent of employees who reported they worked 60 or more hours per week decreased from $28.8 \%$ to $15 \%$ from 1995 to 2005 or by $47.9 \%$.

With every other weekend or partial Saturdays and Sundays off, it is common for pork production workers to put in a 50-hour week. Pork producers responded to this disadvantage by making hours more flexible in 1995. This flexibility declined in 2000 and increased again in 2005. In 1995, more than $30 \%$ of producers and $26 \%$ of employees said their weekend schedules were flexible or staggered by working part of Saturday or Sunday (Table 2). In 2000 , only $22.7 \%$ of producers and $17.8 \%$ of employees reported this flexibility. In 2005 this increased to $26.7 \%$ of producers and $20.6 \%$ of employees reporting flexibilities. Most producers and employees reported two weekends off work a month. The percentage of producers reporting one weekend off work declined from $9.1 \%$ to $5.6 \%$ between 1990 and 2005, compared to employees that reported only one weekend off work declined from $12.2 \%$ to $5.6 \%$. About one in ten employees (11.3\%) indicated they did not have any weekends off.

\section{Dust Mask Use Improves}

The 2005 survey was expanded with new questions on work place safety to gain a better understanding of what producers and employees are doing to protect themselves against exposure to dust, gas and common workplace injuries. Specifically, these new questions asked about the provision and use of ear protection, eye protection, foot protection, and "lock out/tag out" systems for power equipment, in addition to the questions on dust mask and respirators provision and use from previous surveys.

While most producers provided dust masks, they were not used by most employees. About nine in ten producers $(89.2 \%)$ and employees $(92.2 \%)$ indicated they had dust masks or respirators provided (Table 3 ). However, only $34.5 \%$ of the producers and $25.4 \%$ of the employees used them. However, more producers are using dusk mask and respirators now when compared to 1990 , which is goods news given the decline in use reported in 2000. For employees, the percentage using a dust mask also declined in 2000. However, dust mask and respirator use also increased for employees in 2005. Still, unlike producers, the percentage of employees who reported using dust mask and respirators in 2005 is not as high as it was in 1990. Mask use is low, even though masks and respirators are more available, as is the training on how to properly use them. In 2000, almost $90 \%$ of employees indicated dust masks and respirators were supplied by their employers compared to only $70 \%$ in 1990 . Just more than a third of employees indicated they were trained to use 
dust masks and respirators in 1990; by 2000, that number increased to almost half; similar to the 2005 level.

This represents a potential problem. By failing to use the dust mask or respirator provided by an employer, employees risk their health and are more likely to require sick days or file for disability or workers' compensation. Either way, the cost of employment to producers increases.

Ear protection was more widely used than was dusk masks or respirators. Of the employees, $64.5 \%$ used ear protection: eight in ten (83.8\%) had it available. Ear protection was offered by $64.9 \%$ of producers. Eye protection was available for $47 \%$ of producers and $61.2 \%$ of employees. About one in three employees $(36.9 \%)$ use eye protection.

Protective footwear was provided to about one half $(55.7 \%)$ of the employees. About one in three producers (37.3\%) provided it. A 'lock out/tag out' system for power equipment was available for $46.5 \%$ of employees and provided by $29.8 \%$ of producers.

\section{Work Environment}

Both producers and employees believe they have favorable work environments. Furthermore, both have reported continued improvement over time. In $1990,79.5 \%$ of producers and $74.7 \%$ of employees reported an excellent of good work environment. In $2005,89.1 \%$ of producers and $86.2 \%$ of employees reported excellent or good work environments. In 1990 , only $1.4 \%$ of producer reported a poor work environment a value that has consistently fallen to a low of $0.3 \%$ in 2005 . Similarly, only $2.6 \%$ of employees reported a poor work environment in 1990 , a value that has also consistently fallen to low of $2 \%$ in 2005 .

\section{Personnel Management}

The rapid increase in the size of hog production facilities and their increased reliance on hired labor requires producers to develop new skills in personnel management. The first lesson in personnel management for producers is that most employees want to do a good job and be proud of their work. Therefore, when an employee fails to live up to a producer's expectations, it is usually due to one of two reasons. The employee either lacks the required skills to perform the job properly, or he or she does not understand what is expected. Most people like to avoid uncertainty whenever possible. This is especially true of new employees who can have high levels of uncertainty and anxiety. Anxiety worsens when the employee does not have a clear understanding of a job's responsibilities and the employer's expectations.
Producers can systematically and effectively communicate job responsibilities and expectations through the use of employee handbooks and written job descriptions and work plans. Putting responsibilities and expectations in writing gives employees a tangible reference. In addition, frequent work reviews and formal evaluation procedures can serve to guide employees and let them know how they are doing. When an employee has exceeded expectations, formal evaluations provide a wonderful opportunity to acknowledge a job well done.

The surveys indicate that the majority of producers do not take advantage of employee handbooks, written job descriptions and work plans. Still, the percentage of producers using employee handbooks nearly doubled over the 1990-2000 time period increasing from $12 \%$ in 1990 to $22.2 \%$ in 2000 (Table 4). However, it fell back to $21 \%$ in 2005. Similar trends were seen in the percentage of producers using written job descriptions, which increased from $24.6 \%$ to $32.7 \%$ from 1990 to 2000 and decreased to $26.6 \%$ by 2005 . The proportion of producers using written work plans dropped from $57.2 \%$ to $49 \%$ from 1990 to 2000 and was $50.4 \%$ in 2005. More producers are currently reviewing work plans daily and fewer monthly than was the situation in 2000. The percent of producers reviewing work plans daily increased from $35 \%$ to $49 \%$ from 2000 to 2005. This puts it back to the level it was in 1995. The frequency of employee evaluation appears to have declined from 1995 to 2005 . In 1995 about one in five $(20.8 \%)$ producers indicated they conducted quarterly evaluations. This declined to $9.9 \%$ in 2005 which is a $52 \%$ decline. Semi-annual evaluations declined as well. The number reporting annual evaluations increased from $26.3 \%$ to $36.8 \%$. Those indicating they did not do any formal evaluations increased from $25.9 \%$ to $33.5 \%$.

About one in four $(25.1 \%)$ producers indicated that they have a training program for new employees. About one in three (30.1\%) indicated they have an on-going training program.

Some producers indicated that formal evaluations were done 'as needed' and there was not an established frequency of evaluations. For producers responding with "as needed," a word of caution: It is too easy to review an employee's work and conduct a formal evaluation only when the employee's performance is poor. This approach misses the valuable opportunity to recognize employees for all they have done right.

A more in-depth analysis of the producer responses helped to identify characteristics common to those who use handbooks, written job descriptions, written work plans and formal evaluations. Generally, this analysis revealed: Employee 
handbooks were used more often by producers that were younger, had more employees, produced more hogs annually, and operated in the Southeast or West. Written job descriptions were used more often by producers that were younger, more educated, had more employees, produced more hogs annually, and operated in the West. Written work plans were used more often by producers that more educated, produced more hogs annually, and operated in the West. Formal evaluations were used more often by producers that were more educated, had more employees, produced more hogs annually, and operated in the West.

\section{Management Weaknesses}

When producers were asked to evaluate their weaknesses in personnel management, the most frequent responses were similar in 1995, 2000, and 2005. Few training or growth opportunities and weak benefit packages were chosen by about a third of all producers in 2005. They were the first and second most frequent responses in 2005 (Table 5).

Motivating employees and the lack of a welldeveloped work plan were reported by about onefourth of producers in 2005. They were the first and fourth most frequent responses in 2000. Producers were less concerned about their ability to communicate with employees in 2005 than they were in 1995 . This declined from $28.4 \%$ to $19 \%$ or by $33 \%$. They were also less concerned about excessive hours worked. This showed a $58.2 \%$ decline from 1995 to 2005 . A weak salary level also had a lower level of concern and exhibited a $43 \%$ decline from $26.2 \%$ in 1995 to $14.9 \%$ in 2005 .

\section{Employee Satisfaction}

Happy, satisfied employees are more productive. Satisfied employees tend to work harder and are less likely to call in sick. Employees who feel they are making positive contributions and are valued by their employer will generally be more satisfied with their work. Employee satisfaction was high in 2005; $79.9 \%$ were either satisfied or very satisfied, slightly higher than in 1995 (Table 6). However, keep in mind, this survey only measures employees still on the job, having no way to gauge those who were unsatisfied and left the industry.

More than $96 \%$ of the employees who ranked their work environment as "excellent" also reported they were satisfied or very satisfied in 1995, 2000, and 2005 (Table 6). For employees reporting a "good" work environment, the majority $(87 \%$ in $2005,86.5 \%$ in 2000 and $83.7 \%$ in 1995 ) reported they were satisfied or very satisfied with their jobs. Of the employees who reported a "fair" work environment, $53.6 \%$ in $2005,62.4 \%$ in 2000 and
$49.1 \%$ in 1995 reported a need for change. For employees who reported a poor working environment, about one in five in 2005, more than one in four in 2000 and two in five in 1995 reported satisfaction as poor. These results clearly demonstrate the strong effect of an employee's work environment on job satisfaction.

When asked how their employer could make the job more appealing, about half of employees chose a salary that better reflected their work (Table 7).

However, the importance of this declined from 55.8\% in 2000 to $46.4 \%$ in 2005 . Still, more than one third said better communication would help. While about one-third felt more personal recognition would help. The importance of an improved benefits package fell dramatically from $39.6 \%$ in 2000 to $22.1 \%$ in 2005 , a $44 \%$ decline. The importance of a more challenging job declined from 2000 to 2005.

For the most part, producers understand what will make their operation more appealing. While the order changed between 1995, 2000, and 2005, the five most common responses were: a salary that better reflects employee's work, fewer hours, improved benefits, better communication and more personal recognition from employers.

\section{Future Goals}

Employee aspirations and attitudes toward the pork industry have changed over time, too. Most remarkable is the fact that fewer and fewer employees want to own their own operations (Table 8). In 1990, nearly three-fourths held that goal. By 1995 about 55\% said they'd like to own their own hog operation. By 2000, that number fell to about $40 \%$ and remained there in 2005. Older employees and those with more education are less likely to want their own operation. The same is true for women, employees working in operations that produce more hogs annually, and employees working for operations in the Northeast. Furthermore, the percentage of employees who agreed their salary and benefits were competitive in their community increased modestly from $76.1 \%$ to $78.6 \%$ between 1990 and 2000 , and is at $81.4 \%$ in 2005 . Women are less likely to agree that their salary and benefits are competitive in their community.

In 1995 , about $90 \%$ of employees agreed that their job was good training for career advancement. However, that number fell to $83.5 \%$ in 2000 and increased back to $86.9 \%$ in 2005 . Older and more educated employees are less likely to agree that the job is good training for career advancement, while those working for operations with more full-time employees are more likely to agree. Still, about six in ten $(63.2 \%)$ felt that chances for advancement were limited in their operation, an increase from 
$58.7 \%$ in 2000 . Younger employees and those working for operation that produce more hogs annually are more likely to see opportunities for advancement with their current employer.

The percentage of employees who agreed to wanting a life-long career managing a hog operation increased from $67.4 \%$ in 1990 to $69.7 \%$ in 1995 before falling to $64.1 \%$ in 2000 and $58.9 \%$ in 2005 . Older and more educated employees are less likely to be interested in making a lifelong career out of managing a hog farm. The declining interest in managing an operation is hard to explain. One possibility is that, as the absolute number of operations decreases, employees see less opportunity to move up. Four of five employees agreed that their present job was fulfilling. Women and employees working for operation in the Northeast were less likely to feel this way. About four in five (75.6\%) of employees felt their employer was sensitive to their personal needs in 2005 , an increase from $71.1 \%$ who felt so in 2000. Employees working for operations in the Northeast are less likely to feel their employers were sensitive to their personal needs.

\section{Acknowledgements}

Appreciation is expressed to the National Pork Board for providing funding for the study. 
Table 1: Average Hours a Producer Expects a Full-Time Employee to Work and the Average Hours Worked by an Employee.

\begin{tabular}{|c|c|c|c|c|c|c|c|c|}
\hline \multirow[b]{2}{*}{ Hours/Week } & \multicolumn{4}{|c|}{ Producer } & \multicolumn{4}{|c|}{ Employee } \\
\hline & 2005 & 2000 & 1995 & 1990 & 2005 & 2000 & 1995 & 1990 \\
\hline & \multicolumn{4}{|c|}{ Percent } & \multicolumn{4}{|c|}{ Percent } \\
\hline 20 or less & 7.0 & 2.3 & 6.8 & 3.9 & 9.8 & 5.8 & 6.9 & 14.8 \\
\hline $21-30$ & 5.4 & 2.3 & 3.8 & 3.4 & 3.7 & 3.2 & 4.6 & 7.4 \\
\hline $31-40$ & 24.7 & 16.9 & 18.7 & 17.8 & 13.9 & 10.2 & 7.8 & 9.4 \\
\hline $41-50$ & 50.3 & 65.4 & 52.1 & 52.0 & 44.9 & 45.7 & 36.8 & 33.0 \\
\hline $51-60$ & 7.5 & 6.9 & 9.1 & 12.1 & 12.7 & 14.7 & 15.1 & 12.4 \\
\hline \multirow[t]{3}{*}{60 or more } & 5.2 & 6.2 & 9.4 & 10.8 & 15.0 & 20.4 & 28.8 & 23.0 \\
\hline & \multicolumn{4}{|c|}{ Average } & \multicolumn{4}{|c|}{ Average } \\
\hline & 43.2 & 46.5 & 45.2 & 46.7 & 45.3 & 48.7 & 49.7 & 45.2 \\
\hline
\end{tabular}

Table 2: Number of Weekends an Employee Has off per Month.

\begin{tabular}{|c|c|c|c|c|c|c|c|c|}
\hline & \multicolumn{4}{|c|}{ Producer } & \multicolumn{4}{|c|}{ Employee } \\
\hline & 2005 & 2000 & 1995 & 1990 & 2005 & 2000 & 1995 & 1990 \\
\hline & \multicolumn{4}{|c|}{ Percent } & \multicolumn{4}{|c|}{ Percent } \\
\hline 1 Weekend off & 5.6 & 5.4 & 7.5 & 9.1 & 5.6 & 5.4 & 6.0 & 12.2 \\
\hline 2 Weekends off & 41.0 & 40.2 & 37.9 & 43.0 & 36.8 & 43.0 & 37.7 & 39.7 \\
\hline 3 Weekends off & 10.2 & 14.3 & 9.5 & 9.5 & 13.2 & 12.8 & 9.0 & 7.9 \\
\hline 4 Weekends off & 6.6 & 8.9 & 7.4 & 10.8 & 12.6 & 10.3 & 9.0 & 11.1 \\
\hline No Weekends off & 10.0 & 8.4 & 6.9 & 14.3 & 11.3 & 10.8 & 11.8 & 19.4 \\
\hline Flexible or Partial & & & & & & & & \\
\hline Weekends off & 26.7 & 22.7 & 30.9 & 13.3 & 20.6 & 17.8 & 26.5 & 9.7 \\
\hline
\end{tabular}

Table 3: Producer Provision and Employee Use of Protective Equipment and Training.

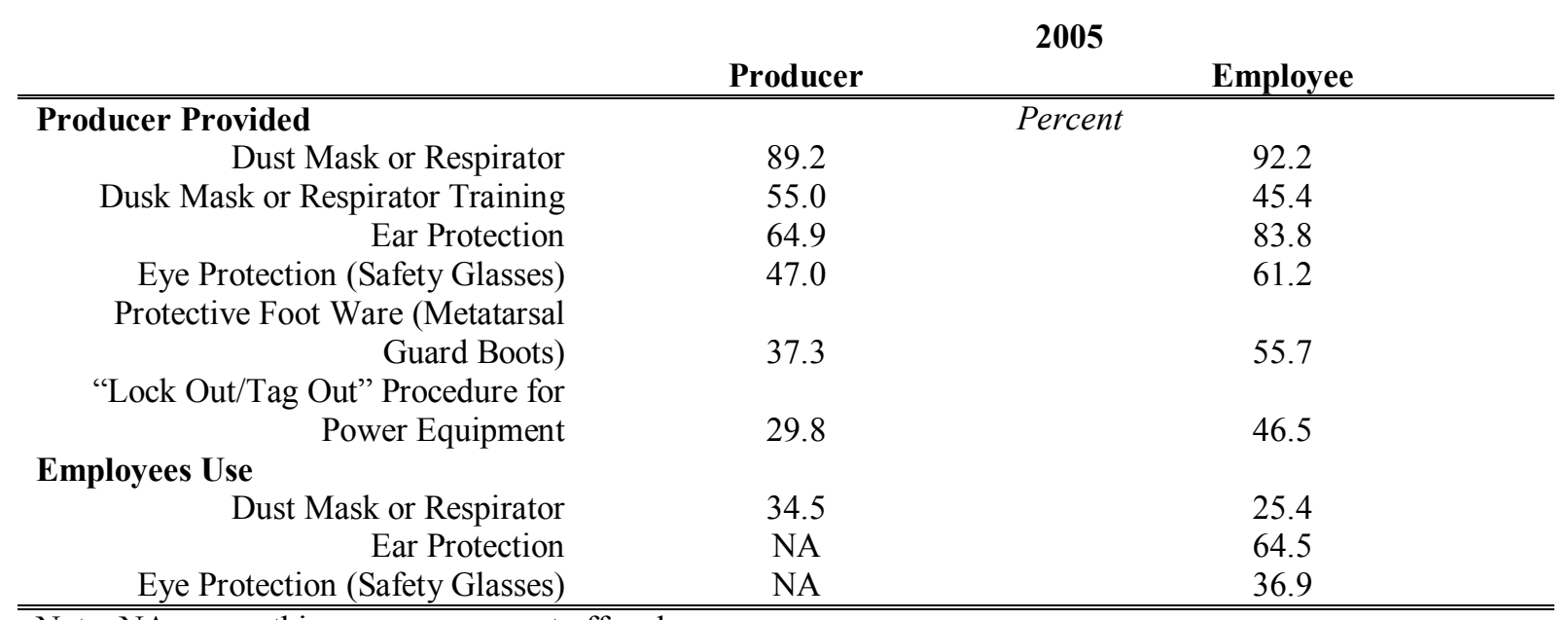

Note: NA means this response was not offered. 
Table 4: Producer Management Practices.

\begin{tabular}{ccccc} 
& $\mathbf{2 0 0 5}$ & $\mathbf{2 0 0 0}$ & $\mathbf{1 9 9 5}$ & $\mathbf{1 9 9 0}$ \\
\hline \hline & & Percent & & Percent \\
Provide Employee Handbook & 21.0 & 22.2 & 12.8 & 12.0 \\
Provide Written Job Description & 26.6 & 32.7 & 24.3 & 24.6 \\
Provide Work Plan & 50.4 & 49.0 & 51.5 & 57.2 \\
Frequency of Work Plan Review & & & & \\
Daily & 49.0 & 35.0 & 47.6 & 53.6 \\
Weekly & 26.7 & 27.4 & 27.1 & 24.1 \\
Monthly & 15.0 & 17.5 & 15.2 & 10.0 \\
Other & 9.3 & 20.2 & 10.0 & 12.4 \\
Have Formal Evaluations & 22.0 & 23.3 & 18.1 & NA \\
Frequency of Evaluations & & & & \\
Quarterly & 9.9 & 11.2 & 20.8 & NA \\
Semi-Annually & 10.8 & 15.8 & 13.2 & NA \\
Annually & 36.8 & 27.5 & 26.3 & NA \\
Never & 33.5 & 20.0 & 25.9 & NA \\
Other & 9.0 & 25.5 & 13.8 & NA \\
New Employee Training Program & 25.1 & NA & NA & NA \\
On-Going Employee Training Program & 30.1 & NA & NA & NA \\
\hline \hline
\end{tabular}

Note: NA means this response was not offered.

Table 5: Areas Identified by Producers as Greatest Weakness in Personnel Management.

\begin{tabular}{rccc} 
& $\mathbf{2 0 0 5}$ & $\mathbf{2 0 0 0}$ & $\mathbf{1 9 9 5}$ \\
\hline \hline Few Training or Growth Opportunities & 32.7 & Percent & \\
Weak Benefit Package & 26.5 & 29.3 & 40.0 \\
Motivating Employees & 25.3 & 29.9 & 32.4 \\
Lack Well Developed Work Plans & 22.0 & 23.6 & $\mathrm{NA}$ \\
Poor Communications with Employees & 19.0 & 23.6 & 32.7 \\
Exor Recruiter/Trouble Getting Applicants & 18.8 & 20.3 & 28.4 \\
Excessive Hours Worked & 15.2 & 12.1 & 16.5 \\
Weak Salary Level & 14.9 & 28.2 & 36.4 \\
Resolving Conflicts & 11.9 & 21.1 & 26.2 \\
Getting Employees to Share Their Ideas & 11.3 & 10.1 & $\mathrm{NA}$ \\
Do Not Screen Applicants Well Enough & 11.0 & 15.9 & $\mathrm{NA}$ \\
Retaining Qualified Employees & 10.7 & 12.1 & 14.6 \\
Other & 6.3 & 13.4 & $\mathrm{NA}$ \\
Have Poor Working Conditions for & & 4.9 & $\mathrm{NA}$ \\
Employees & 4.5 & 5.8 & 9.7 \\
\hline \hline
\end{tabular}

Note: Producers were asked to choose as many as three responses. NA means this response was not offered. 
Table 6: Employee's Level of Job Satisfaction by Rating of Their Work Environment.

Employee Satisfaction

\begin{tabular}{|c|c|c|c|c|}
\hline $\begin{array}{l}\text { Work Environment } \\
\text { Rating }\end{array}$ & Very Satisfied & Satisfied & Needs Changes & Poor \\
\hline$\overline{2005}$ & \multicolumn{4}{|c|}{ Percent } \\
\hline Excellent & 72.7 & 24.6 & 2.7 & 0.0 \\
\hline Good & 25.7 & 61.3 & 12.7 & 0.3 \\
\hline Fair & 4.3 & 39.1 & 53.6 & 2.9 \\
\hline Poor & 10.0 & 0.0 & 70.0 & 20.0 \\
\hline 2000 & & & & \\
\hline Excellent & 70.9 & 24.9 & 3.8 & 0.4 \\
\hline Good & 25.9 & 60.6 & 13.1 & 0.5 \\
\hline Fair & 2.8 & 31.2 & 62.4 & 3.7 \\
\hline Poor & 0.0 & 14.8 & 55.6 & 29.6 \\
\hline 1995 & & & & \\
\hline Excellent & 71.1 & 24.9 & 3.7 & 0.3 \\
\hline Good & 32.0 & 51.7 & 15.5 & 0.8 \\
\hline Fair & 10.9 & 35.2 & 49.1 & 4.8 \\
\hline Poor & 0.0 & 15.4 & 41.0 & 43.6 \\
\hline
\end{tabular}

Table 7: Areas Identified by Employees That Make an Operation More Appealing.

\begin{tabular}{rlll} 
& $\mathbf{2 0 0 5}$ & $\mathbf{2 0 0 0}$ & $\mathbf{1 9 9 5}$ \\
\hline \hline Salary Better Reflection of Your Work & 46.4 & Percent & \\
Better Communication & 34.2 & 55.8 & 51.0 \\
More Personal Recognition from Employer & 32.4 & 36.6 & 39.8 \\
Fewer Hours & 29.3 & 32.3 & 28.1 \\
Improved Benefit Package & 22.1 & 29.3 & 29.2 \\
More Opportunity For Advancement & 19.4 & 39.6 & NA.4 \\
Better Working Conditions & 11.7 & 12.9 & 18.6 \\
More Training Opportunities & 10.4 & 13.9 & 17.8 \\
More Challenge and Responsibility & 8.1 & 15.2 & 14.2 \\
Clearer Defined Work Plan & 7.2 & 12.4 & 12.6 \\
Other & 6.3 & 11.4 & 10.5 \\
\hline \hline
\end{tabular}

Note: Employees were asked to choose as many as three responses. NA means this response was not offered. 
Table 8: Job Satisfaction and Future Goals.

\begin{tabular}{|c|c|c|c|c|}
\hline \multirow[b]{2}{*}{ Statement } & \multicolumn{4}{|c|}{ Employees Agreeing with Statement } \\
\hline & 2005 & 2000 & 1995 & 1990 \\
\hline & \multicolumn{4}{|c|}{ Percent } \\
\hline $\begin{array}{l}\text { My salary and benefits are } \\
\text { competitive with other job } \\
\text { opportunities in my community. }\end{array}$ & 81.4 & 78.6 & 78.9 & 76.1 \\
\hline $\begin{array}{l}\text { This job is a good training ground to } \\
\text { prepare me for advancement or to }\end{array}$ & & & & \\
\hline operate my own hog operation. & 86.9 & 83.5 & 89.5 & 93.2 \\
\hline $\begin{array}{l}\text { This job is a good training ground to } \\
\text { prepare me for career advancement. }\end{array}$ & 64.9 & NA & NA & NA \\
\hline $\begin{array}{l}\text { This job is a good training ground to } \\
\text { prepare me for my own hog } \\
\text { operation. }\end{array}$ & 78.3 & NA & NA & NA \\
\hline $\begin{array}{l}\text { I would like to make a life long } \\
\text { career out of managing a hog } \\
\text { oneration. }\end{array}$ & & & & \\
\hline $\begin{array}{l}\text { operation. } \\
\text { I wish to own a hog operation }\end{array}$ & 58.9 & 64.1 & 69.7 & 67.4 \\
\hline $\begin{array}{l}\text { someday. } \\
\text { The chance for advancement are }\end{array}$ & 40.8 & 39.9 & 54.9 & 74.6 \\
\hline limited in this hog operation. & 63.2 & 58.7 & 55.5 & 58.9 \\
\hline $\begin{array}{l}\text { I find my present job challenging } \\
\text { and fulfilling. }\end{array}$ & 80.0 & 78.5 & 80.5 & 82.4 \\
\hline $\begin{array}{l}\text { My employer is sensitive to my } \\
\text { personal needs and interests. }\end{array}$ & 75.6 & 71.1 & 72.7 & 76.6 \\
\hline
\end{tabular}

Note: NA means this response was not offered. 
Iowa State University does not discriminate on the basis of race, color, age, religion, national origin, sexual orientation, gender identity, sex, marital status, disability, or status as a U.S. veteran. Inquiries can be directed to the Director of Equal Opportunity and Diversity, 3680 Beardshear Hall, (515) 294 - 7612 . 